\title{
Empty Sella Syndrome
}

National Cancer Institute

\section{Source}

National Cancer Institute. Empty Sella Syndrome. NCI Thesaurus. Code C84686.

A syndrome characterized by flattening or regression of the pituitary gland within the sella turcica cavity, resulting in an MRI image of an empty sella turcica. Signs and symptoms are secondary to pituitary gland hypofunction. 